\title{
Skiing injuries: a study from a Danish community
}

\author{
B. Møller-Madsen, MD, B.W. Jakobsen, MD and I. Villadsen MD \\ University Department of Orthopaedic Surgery, Division of Sports Traumatology, Aarhus Amtssygehus and \\ Aarhus Kommunehospital, DK-8000 Aarhus C, Denmark
}

\begin{abstract}
A Danish investigation of skiing injuries is presented from the casualty wards of two hospitals. The material consisted of 119 skiing injuries. Fifty-three per cent of the patients were women. Eighty-three injuries occurred abroad, mainly in Austria and Norway. Injury rate was not related to sex. The highest injury rate was found in the age group 20 to 29 years old. The most frequent injuries were sprains (knee 43, finger 14), fractures (39) and contusions (19). Injuries requiring hospitalization were common. None of these resulted in permanent major disability.
\end{abstract}

Keywords: Skiing, injury rate, fracture type

\section{Introduction}

Skiing is a sport that is highly dependent on technique. Body position and balance, endurance and muscle power are all factors that contribute substantially to skiing ability, making training important in injury prevention.

In Denmark, however, training is limited by the fact that it is a lowland country with a relatively mild and rainy winter. This makes the skiing season short and stimulates skiers to go abroad for skiing.

In order to elucidate type and severity of skiing injuries among Danish skiers and their socioeconomic consequences, a prospective study was undertaken in the community of Aarhus.

\section{Materials and methods}

During the winter season, December 1986 to March 1987, all patients suffering from skiing injuries who consulted the casualty departments of Aarhus Amtssygehus and Aarhus Kommunehospital were registered. A questionnaire including the following parameters was filled in by the patients: age, sex, time, date and geographic locality of the accident. In addition, equipment was described including the type of skis. Patients gave their informed consent to participate prior to physical examination.

Aarhus has a total of 253753 inhabitants. Statistical analysis was carried out using Chi-square test. P values less than .005 were considered to be statistically significant.

Address for correspondence: B. Møller-Madsen MD, Institute of Anatomy, University of Aarhus, DK-8000 Aarhus C, Denmark

(C) 1990 Butterworth-Heinemann Ltd 0306-4179/90/020123-02

\section{Results}

A total number of 119 injuries were registered. Sixty-one injuries were related to alpine skiing and 58 injuries to cross-country skiing. Eighty-three (70 per cent) of all injuries were contracted abroad, mainly in Austria or Norway.

Distribution according to age group and sex is shown in Table 1. Unlike the sex distribution, injury risk was age group related. The age group 20 to 29 years old had a significantly higher injury rate than the remaining groups $(p<0.001)$. The age range from seven to 63 years old. The mean age of the injured patients was 28.0 years old $(\mathrm{SD}=11,9)$.

Anatomical localization of the injury is shown in Table 2. The most common injuries (48 per cent) were sprains, usually involving the knee or finger. Fractures occurred in 33 per cent of injured skiers, while contusions, often to the torso, were sustained in 15 per cent. Concussion occurred in one case only and did not require overnight hospitalization for observation.

Twenty-nine patients in all required hospitalization. Table 3 shows their diagnosis. These patients required a total of 179 days in hospital. The mean was 6.2 days $(S D=9,7)$ and the range was one to 54 days. The 179 days took up 1.9 per cent of the total amount of hospitalization days used by the two orthopaedic departments. The average price for one day of hospitalization was 3000 DKK per bed, making a total of $537.000 \mathrm{DKK}$ for the injured skiers. All patients required out-patient follow-up. No serious or major debilitating injuries occurred during the period of our study.

\section{Discussion}

Sprains accounted for over 40 per cent of the registered injuries. This is consistent with previous reports ${ }^{1}$. Sprains to the ulnar collateral ligament of the metacarpophalangeal joint (skiers' thumb), probably one of the most common injuries in alpine skiers $^{2,3}$ and cross-country skiers ${ }^{4}$, was further confirmed by this study; nine of the 14 finger sprains were skier's thumb.

Knee sprains were found to account for 25 per cent of all alpine skiing injuries ${ }^{5}$. In the present study, sprains to the knee during alpine skiing were responsible for around 40 per cent of injuries. The higher rate can be explained by the registration 
Skiing injuries: B. Meller-Madsen MD, B.W. Jakobsen MD and I. Villadsen

Table 1. Distribution of ski injuries on age groups and sex

\begin{tabular}{|c|c|c|c|c|c|c|}
\hline Age & $<19 y r$ & $20-29 y r$ & $30-39 y r$ & $40-49 y r$ & $>50 \mathrm{yr}$ & \\
\hline $\begin{array}{l}\text { Male } \\
\text { Female } \\
\text { Inhabitants } \\
\text { Injury rate }\end{array}$ & $\begin{array}{c}15 \\
12 \\
60.823 \\
0,4 \times 10^{-3}\end{array}$ & $\begin{array}{c}20 \\
26 \\
52.462 \\
0,9 \times 10^{-3}\end{array}$ & $\begin{array}{c}11 \\
15 \\
41.290 \\
0,6 \times 10^{-3}\end{array}$ & $\begin{array}{c}6 \\
8 \\
31.747 \\
0,4 \times 10^{-3}\end{array}$ & $\begin{array}{c}4 \\
2 \\
67.429 \\
0,09 \times 10^{-3}\end{array}$ & $\begin{array}{l}56 \\
63\end{array}$ \\
\hline
\end{tabular}

method. Injuries registered in the casualty department took into account only the serious injuries.

Ankle fractures have become less common in alpine skiing since the development of tall, rigid ski boots $^{6,7}$. This is confirmed by our result; ankle

Table 2. Type and anatomical location of injury in alpine and cross-country skiing $(n=119)$

\begin{tabular}{|c|c|c|c|c|}
\hline & Total no. & Alpine & \multicolumn{2}{|c|}{ Cross-country } \\
\hline Concussion & 1 & & 1 & \\
\hline $\begin{array}{l}\text { Fracture of clavicle } \\
\text { Fracture of humerus shaft } \\
\text { Shoulder dislocation }\end{array}$ & $\begin{array}{l}3 \\
\mathbf{1} \\
\mathbf{3}\end{array}$ & $\begin{array}{l}1 \\
1\end{array}$ & $\begin{array}{l}2 \\
3\end{array}$ & $6 \%$ \\
\hline Fracture of forearm & 7 & 3 & 4 & $6 \%$ \\
\hline $\begin{array}{l}\text { Fracture of metacarpal bone } \\
\text { Fracture of finger } \\
\text { Finger sprain }\end{array}$ & $\begin{array}{r}4 \\
8 \\
14\end{array}$ & $\begin{array}{l}2 \\
5 \\
6\end{array}$ & $\begin{array}{l}2 \\
3 \\
8\end{array}$ & $22 \%$ \\
\hline $\begin{array}{l}\text { Fracture of ribs } \\
\text { Fracture of femur } \\
\text { Knee sprain } \\
\text { Fracture of tibia shaft } \\
\text { Fracture of ankle } \\
\text { Miscellaneous contusions }\end{array}$ & $\begin{array}{r}1 \\
1 \\
43 \\
7 \\
7 \\
19\end{array}$ & $\begin{array}{r}1 \\
25 \\
7 \\
3 \\
8\end{array}$ & $\begin{array}{r}18 \\
3 \\
11\end{array}$ & $\begin{array}{r}36 \% \\
6 \% \\
6 \% \\
15 \%\end{array}$ \\
\hline Total & 119 & 62 & 57 & \\
\hline
\end{tabular}

Table 3. Hospitalizations resulting from skiing injuries

\begin{tabular}{lcc}
\hline Diagnosis & Alpine & Cross-country \\
\hline Fracture of humerus shaft & 1 & \\
Fracture of metacarpal bone & 2 & 2 \\
Fracture of finger & 1 & 2 \\
Finger sprain & 1 & \\
Fracture of femur & 1 & \\
Knee sprain & 1 & 3 \\
Fracture of tibia & 2 & 10 \\
Fracture of ankle & & \\
Total & 19 & \\
\hline
\end{tabular}

fractures were responsible for 6 per cent of all the injuires registered.

The socio-economic effects of skiing injuries per se to the patients' welfare are considerable. As well as expensive hospitalization, a prolonged period of rehabilitation is often required before they are advised to resume work.

In summary, a prospective study examining all skiing injuries occurring among a well defined population in relation to recreational skiing reveals that the majority of skiing injuries requiring referal to a casualty department or admission to an orthopedic ward are sprains, fractures and contusions. None of the injuries resulted in permanent major disability. Furthermore, the study highlights the need for prophylaxis in order to reduce the injury rate.

\section{Acknowledgement}

The authors wish to thank Ms Jette Johansen for typing the manuscript.

\section{References}

1 Ellison, A.E. Skiing injuries Clin Symp 1977, 29(1), 1-40

2 Eriksson E. Ski Injuries in Sweden. A one year survey Orthop Clin North Am 1976, 7, 3-9

3 Wright J. Skier's thumb Ski patrol magazine 1986, 22, 38-39

4 Hixon E.G. Injury pattern in cross-country skiing Physician sportsmed 1981, 9(12), 45-55

5 Clancy, W.G. and McConkey, J.P. Nordic and alpine skiing in Schneider, R.C., Kennedy, J.C. and Plant, M.L. (eds) 'Sports injuries: Mechanisms, prevention and treatment' Baltimore, Williams \& Wilkins, 247-270

6 Johnson, R.J., Ettlinger, C.F., Campbell, R.J. et al. (1980) Trends in skiing injuries: Analysis of a six year study (1972-1978) Am J Sport Med 1980, 8, 106-113

7 Tapper, E.M. Ski injuries from 1939 to 1976: The Sun Valley experience Am J Sport Med 1978, 6, 114-121 